\title{
Performance-Based Evaluation of Large Steel-Framed Structures in the Overall Fire Process
}

\author{
Guoqing Zhu, ${ }^{1}$ Guowei Zhang, ${ }^{1}$ Guanglin Yuan, ${ }^{2}$ and Qingtao $\mathrm{Li}^{2}$ \\ ${ }^{1}$ School of Safety Engineering, China University of Mining and Technology, Xuzhou 221116, China \\ ${ }^{2}$ Jiangsu Key Laboratory for Environmental Impact and Structural Safety in Civil Engineering, Xuzhou 221116, China
}

Correspondence should be addressed to Guowei Zhang; zgw119xz@126.com

Received 17 April 2014; Accepted 11 July 2014; Published 24 July 2014

Academic Editor: Bernard J. Geurts

Copyright (c) 2014 Guoqing Zhu et al. This is an open access article distributed under the Creative Commons Attribution License, which permits unrestricted use, distribution, and reproduction in any medium, provided the original work is properly cited.

\begin{abstract}
This paper proposes a systematic analysis of fire hazards within an oversized steel-framed building that is taller and wider than usual, using a performance-based approach. We put forth both the method and the performance criteria for performance-based fire design of oversized steel-framed buildings and quantitatively evaluate the hazard factors (smoke temperature, smoke visibility, smoke toxicity, and structural collapse) in fire condition. FDS large eddy simulation and a modified temperature rise model of oversized steel structures were proposed for the quantitative analysis of hazard factors. Furthermore, we also studied evacuation process from oversized buildings and found that the Pathfinder model (developed based on water conservation model and behavior model) can accurately predict the evacuation process from oversized buildings based on our experimental study of an evacuation from a stadium. By comparing the time of occurrence of fire hazard factors (smoke temperature, smoke visibility, smoke toxicity, and structural collapse) and the time needed for safe evacuation, we could conduct a quantitative fire risk assessment on personal evacuation. And the time of occurrence of fire hazard factors can also provide a theoretical reference for emergency rescuers.
\end{abstract}

\section{Introduction}

Heat and smoke would be generated in case of fire. Smoke hazards such as smoke temperature, toxicity, and visibility can be dangerous for evacuees. In addition, the generated heat would heat the structural number in the whole fire process. Steel structures are advantageous due to their high strength, high plasticity, and durability. Steel structures are ideal for the construction of buildings that are oversized, defined as being taller and wider in space than conventional buildings, and are currently used extensively for numerous public buildings. However, steel structures do not tolerate fires well, as they rise quickly in temperature and lose significant amounts of their strength and elasticity. In fact, the safety of personnel who are evacuated from a fire, as well as emergency workers, can be severely endangered when the steel temperature reaches $500 \sim 600^{\circ} \mathrm{C}$ [1]. For example, on April 9, 2003, a fire in the workshop in Qingdao, China, caused the collapse of the steel roof truss and led to the death of 21 employees who were not evacuated in a timely manner. On September 2, 2013, another fire in a steel structure workshop in Wenzhou, China, caused the collapse of the steel roof and led to the death of five people. Thus, the risk of localized fire in oversized spaces needs quantitative assessment urgently; it is very important to effectively study the overall fire hazards in steel-framed buildings and quantitatively evaluate evacuation safety and the time available for emergency rescue. At present, studies analyzing fire hazards in oversized steel-framed buildings mainly focus on the effects of rising temperatures on the steel structure and the stability of steel in a fire by computer simulation. Researchers (such as Ghojel and Wong, 2005 [2]; Dwaikat and Kodur, 2012 [3]; Kay et al., 1996 [4]; Gardner and Ng, 2006 [5]; Wald et al., 2006 [6]; Barthelemy, 1976 [7]; and Shi et al., 2011 [8]) have studied the temperature rise model of steel components in a fire, divided the amount of heat absorbed by smoke thermal radiation and smoke thermal convection, and used the classic thermal radiation and convective heat transfer models to calculate the heat exchange between steel and smoke. With respect to the stability of steel by computer modeling, Rubert and Schaumann conducted a fire resistance test on a series of steel frames in various forms and obtained their temperature 
of destruction [9]. Wang made an analysis of the global structural behavior of the 8-storey steel-framed building at Cardington. Results suggested that columns may attain large moments as a result of being pushed by the adjacent hot beams, but as the test column temperatures were low, it was not possible to assess the column failure behavior $[10,11]$. Wald et al. investigated the global structural behavior of a compartment on the 8-storey steel-concrete composite frame building at the Cardington laboratory during a BRE largescale fire test, aimed at the examination of the temperature rise within the various structural elements, the corresponding (dynamic) distribution of internal forces, and the behavior of the composite slab, beams, columns, and connections [12]. Franssen et al. made a number of numerical simulations of the behavior in a real fire of a full-size, loaded, mainly unprotected steel frame [13]. Wong proposed elastic and plastic methods for numerical modeling of steel structures subject to fire [14].

From the above summary, it is clear that current studies that analyze the fire hazards in steel-framed buildings are often limited in their scope and rarely consider the many factors in a fire, including smoke, structural collapse, personnel evacuation, and rescue time, and that no method has been proposed to quantitatively evaluate the overall process during a fire within steel-framed buildings. Moreover, these studies often focus only on conventional buildings and rarely cover the fire-resistant design of oversized steel-framed buildings. For example, the classic temperature rise model of steel components is more applicable to conventionally sized buildings, but not to oversized buildings, because the classic temperature rise model fails to take into consideration the direct effect of the thermal radiation of the flame. For oversized buildings, the smoke temperature is relatively low (generally only $200 \sim 500^{\circ} \mathrm{C}$ ) and the thermal radiation and convection effects of smoke are far lower than the thermal effects inside conventional buildings. As a result, the thermal radiation effect of the flame becomes nonnegligible. Particularly, when the flame is close to steel components, its direct thermal radiation effect on steel components becomes more obvious. Our current paper proposes a method to quantitatively evaluate the overall scenario during a fire in oversized steel-framed buildings by adopting a performancebased approach. We put forth methods to predict the smoke hazards, structural collapse, and personnel evacuation in oversized buildings during a fire and modified and verified the temperature rise model and personnel evacuation model of oversized steel structure buildings.

\section{Performance-Based Fire Design of Steel Structures}

With economic growth, ever larger and more architecturally complex buildings are continuously emerging. Numerous new theories, new technologies, new materials, new processes, and new design concepts are extensively applied in architectural design. As a result, conventional prescriptive standards for fire safety cannot meet the actual needs in construction projects. Particularly, in the fire safety design of some oversized buildings (exhibition halls, stadiums, theaters, large workshops and warehouses, etc.), the provisions within existing standards are often inconsistent or inadequate, and sometimes there are no clearly defined existing standards. Therefore, there is an urgent demand for in depth studies on the science of fire safety.

Performance-based fire design requires fire safety demands to be determined based on the structural characteristics of buildings and the developmental characteristics of fire. Adopting deterministic and probability methods, performance-based fire design establishes the fire model and fire scenario of an existing or planned architectural object on the basis of its own characteristics. Computer modeling is used to simulate the occurrence and development of fire, numerically exhibit and embody the spatial and temporal distribution of hazards, and analyze and demonstrate the hazards and risks of fire. Based on the results of simulation and analysis, targeted technical measures are correspondingly implemented to achieve an acceptable fire safety level. The general outline of performance-based fire design is shown in Figure 1.

2.1. Performance Criteria of Performance-Based Fire Design. The first step in the performance-based fire design of steelframed buildings is to define the safety objective of the design. The safety objective should be determined in accordance with the requirements of the risk bearer. The safety objective can be generally summarized as follows: ensure timely personnel evacuation from the building and protect firefighters from structural collapse during the rescue process. In other words, the safety objective lies in ensuring the safety of the occupants and emergency workers and the stability of the structure. However, further analyses are needed in the performancebased fire design in order to express the safety objective in mathematical terms. When a fire occurs in an oversized steelframed building, people begin to evacuate as soon as the fire is detected, and the evacuation process is complete when the last person in the building is in a safe outdoor place. The duration of the evacuation process is known as the time needed for evacuation, abbreviated as $T_{\text {REST }}$. At the same time, the heat and smoke generated by the fire cause danger to the people evacuating from the building. Smoke toxicity, temperature, visibility, and the structure collapse may all cause injuries or death to anyone in the building. The time between the start of a fire and the time point at which the fire hazards exceed the tolerance limit of the human body is called the time available for evacuation, abbreviated as $T_{\mathrm{ASET}}$. Thus, for oversized steel structures, the time available for evacuation is also the time at which various hazard factors become intolerable.

Based on the fire hazard analysis provided by SFPE handbook of fire protection engineering, the fire hazards in oversized steel-framed buildings mainly include visibility, temperature, $\mathrm{CO}$ concentration of the smoke layer, and structural collapse. SFPE handbook has given performance criteria for each hazard. The critical criteria of smoke temperature should not exceed $60^{\circ} \mathrm{C}$ at $2 \mathrm{~m}$ height from the ground, the smoke visibility should not be less than $10 \mathrm{~m}$, and the CO concentration should not exceed $5 \times 10^{-4} \mathrm{~mol} / \mathrm{mol}$. 


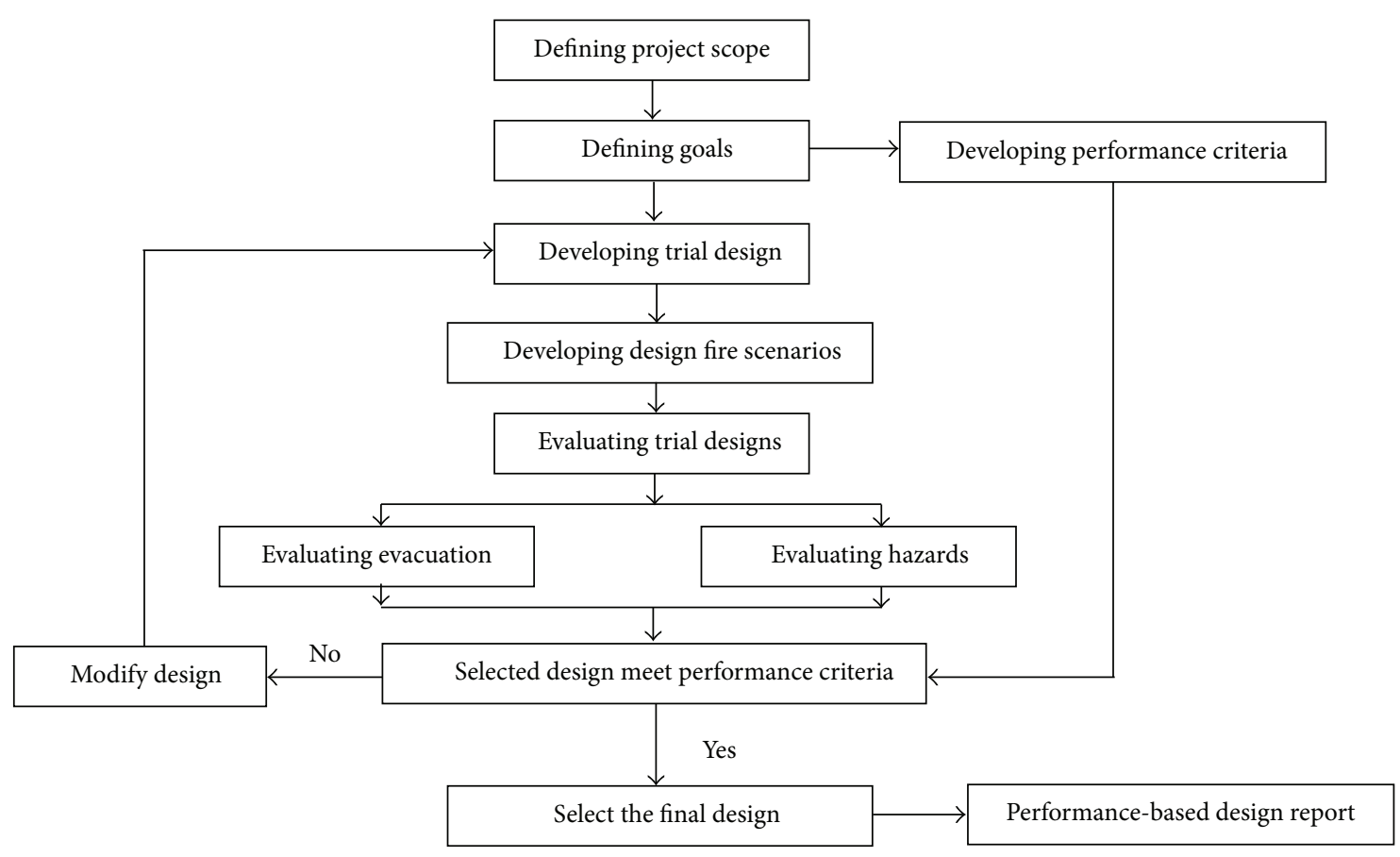

FIGURE 1: General outline of performance-based fire design.

For structural collapse, the basic function of structure is to bear load. During the fire disaster, with the increase of internal temperature of the steel structure, the bearing capacity of steel structure will drop. When the bearing capacity of the structure is equal to the composite effect generated by the external loading (including temperature loading), the structure reaches the limit of bearing capacity in fire. In order to keep steel structure in safety state in fire process, the following requirements should be met. Within the fire resistance time, the bearing capacity of the structure, $R_{d}$, should not be less than the composite effect generated by all forces $S_{m}$. Under various combinations of load effects, the fire resistance of the structure, $t_{d}$, will not be less than the fire resistant limit of the structure, $t_{m}$. Suppose the internal temperature distribution of the structure is certain in fire. If the temperature of a certain internal characteristic point is the critical temperature $T_{d}$ when the structure reaches the limit of bearing capacity, then this critical temperature should not be less than the highest temperature of this characteristic point of the structure within this duration of fire resistance $T_{m}$.

The above three requirements are actually equivalent. In order to keep steel structure in safety in fire process, only one of these requirements must be met. In the fire, the bearing capacity and the duration of fire resistance are not easy to be estimated, while the critical temperature of steel is often used as a bench mark for determining the failure of structural members exposed to fire. In order to provide a relatively simple method for fire protection engineer, SFPE handbook has also given a conservative performance criterion for steel temperature. The critical criteria of steel numbers should not exceed $350^{\circ} \mathrm{C}[16,17]$.

When the time available for evacuation $T_{\text {ASET }}$ is longer than the time needed for evacuation $T_{\mathrm{REST}}$, the people in the building can be evacuated to a safe place before the hazards exceed critical tolerance, and there will be no risk of personal injuries or death. On the contrary, when the time available for evacuation $T_{\mathrm{ASET}}$ is less than the time needed for evacuation $T_{\text {REST }}$, some people in the building may not be able to evacuate before the hazards exceed critical tolerance, and there will be the risk of personal injuries or death. Thus, the safe evacuation from an oversized steel-framed building is determined on the following basis:

$$
T_{\text {ASET }}>T_{\text {REST }} \text {. }
$$

2.2. Design of a Fire Scenario. In order to study the time available for evacuation $T_{\mathrm{ASET}}$ and the time needed for evacuation $T_{\text {REST }}$, it is necessary to design fire scenarios and study the smoke hazards (temperature, visibility, and toxicity), the structural stability, and the time needed for evacuation under different fire scenarios. Theoretically, the designer needs to study the fire hazards and personnel evacuation under all possible fire conditions, resulting in an indefinite number of possible fire scenarios, which is impossible to design in reality. Therefore, the selection of a fire scenario should be based on statistical results or fire hazard evaluation. The fire scenario should be based on the most representative condition; that is, the location, type and load of fire, the reliability of the firefighting system, the characteristics of the buildings and people, and other factors should all be taken into consideration to select the most representative fire scenario as the designed fire scenario.

There are three main factors employed to describe a fire: location of the fire source, fire development model, and maximum heat release rate. These three factors should be determined in designing a fire scenario. In terms of the fire 
source location, a statistical method may be employed to determine the most likely location of fire. If there are no suitable statistical data available, the fire load distribution can be used for evaluation. Without considering the decay phase of fire, the steady fire or $t^{2}$ fire development models may be commonly used as the fire development model in oversized buildings. As supplement, we have proposed a fire rise model for the whole process of localized fires in largespace buildings, as shown in (2). As we all know, the whole process of a localized fire includes growing phase, steady phase, and decay phase. Among them, the heat release rate of the fire at the growing phase increases following the rule of the $t^{2}$ fire model; the heat release rate remains constant at the steady phase, whereas linearly decreases at the decay phase. This model can more accurately and comprehensively reflect the characteristics of localized fires in oversized spaces [18].

Consider

$$
\begin{gathered}
Q=\alpha t^{2} \quad 0 \leq t \leq t_{g}, \\
Q=Q_{\max } \quad t_{g} \leq t \leq t_{d} \\
Q=\frac{t_{s}}{t_{s}-t_{d}} Q_{\max }-\frac{t}{t_{s}-t_{d}} Q_{\max } \quad t_{d} \leq t \leq t_{s},
\end{gathered}
$$

where $Q_{\max }$ is the maximum heat release rate of the fire, $\mathrm{kW}$; $t_{s}$ is total time of the whole process of a fire, $s ; t_{d}$ is time when the fire enters the decay phase, $s$; $t_{g}$ is the time when the fire enters the full developed phase (steady phase), s.

As far as oversized buildings are concerned, the maximum heat release rate of a fire is mainly determined by the effectiveness of the sprinkler system inside the building. For a fire controlled by the automatic sprinkler system, the maximum heat release rate will be controlled under a steady value. When the automatic sprinkler system is in action, the maximum heat release rate could be predicted by

$$
Q_{\max }=\alpha t_{\text {action }}^{2}
$$

where $\alpha$ represents the fire growth coefficient, $\mathrm{kW} / \mathrm{s}^{2} ; t_{\text {action }}$ represents the action time of the automatic extinguishing system, s. When the sprinkler system inside an oversized building loses efficacy, the maximum heat release rate of the fire is mainly determined by the internal fire load of localized combustibles. For a localized fire in an oversized building controlled by fire load, the heat release rate of all the combustibles is generally used in engineering calculation as the maximum heat release rate of the fire described as

$$
Q_{\max }=A_{\max } q
$$

where $A_{\max }$ represents the maximum combustion area of the localized fire, $\mathrm{m}^{2} . q$ represents the heat release rate of a unit area, $\mathrm{kW} / \mathrm{m}^{2}$. CIBSE standards have given recommended value of the maximum heat release rate of a unit area as shown in Table 1.
TABLE 1: Maximum heat release rate of a unit area recommended in CIBSE [15].

\begin{tabular}{lc}
\hline Building occupancy & Heat release rate $/\left(\mathrm{kW} / \mathrm{m}^{2}\right)$ \\
\hline Retail store & 500 \\
Office & 250 \\
Residence & 250 \\
Exhibition hall & 100 \\
\hline
\end{tabular}

\section{Quantitative Analysis of Fire Hazards}

3.1. Quantitative Analysis of Smoke Hazards. Fire simulation technology, based on studies of the basic principles governing the fire development process, establishes a mathematical model to quantitatively calculate various basic parameters of the fire development process and their correlation. Fire simulation technology is able to predictively analyze the visibility, temperature, and toxicity of a smoke layer in the whole fire process. The dynamic fire simulation software (FDS) is currently the most specialized smoke movement simulation platform. FDS employs spatial filtering to simplify the Navier-Stokes equations, which has the characteristics of an elliptic partial differential equation suitable for the simulation of low-rate and heat-convection flow processes. When oversized buildings catch fire, both heat transfer and mass transfer in the fire situation follow the fluid dynamics model as provided below.

Conservation of mass is

$$
\frac{\partial \rho}{\partial t}+\nabla \cdot(\rho u)=m b^{\prime \prime \prime}
$$

Conservation of momentum is

$$
\frac{\partial(\rho u)}{\partial t}+\nabla \cdot(\rho u u)+\nabla P=\rho g+f_{b}+\nabla \cdot \tau_{i j} .
$$

Transport of sensible enthalpy is

$$
\frac{\partial\left(\rho h_{s}\right)}{\partial t}+\nabla \cdot\left(\rho h_{s} u\right)=\frac{D p}{D t}+q^{\prime \prime \prime}-q_{b}^{\prime \prime \prime}-\nabla \cdot q^{\prime \prime}+\varepsilon .
$$

Equation of state for a perfect gas is

$$
p=\frac{\rho R T}{W} .
$$

Combustion model is

$$
\begin{aligned}
\mathrm{C}_{x} \mathrm{H}_{y} \mathrm{O}_{z} \mathrm{~N}_{a} \mathrm{M}_{b}+v_{\mathrm{O}_{2}} \mathrm{O}_{2} \longrightarrow & v_{\mathrm{CO}_{2}} \mathrm{CO}_{2}+v_{\mathrm{H}_{2} \mathrm{O}} \mathrm{H}_{2} \mathrm{O}+v_{\mathrm{CO}} \mathrm{CO} \\
& +v_{\mathrm{S}} \mathrm{S}+v_{\mathrm{N}_{2}} \mathrm{~N}_{2}+v_{\mathrm{M}} \mathrm{M}
\end{aligned}
$$

Lots of researches have shown that large eddy simulation technology of FDS can accurately predict the hazards distributions of smoke in the whole process of fire $[19,20]$. Taking an oversized steel-warehouse fire as an example, large eddy simulation technology of FDS is applied to predict the smoke hazards. The simulation fire is $16.9 \mathrm{MW}$ occurring in a 


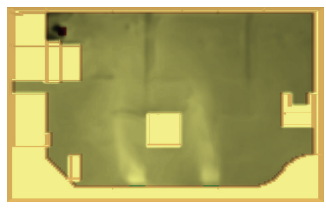

Smoke spreading at $500 \mathrm{~s}$

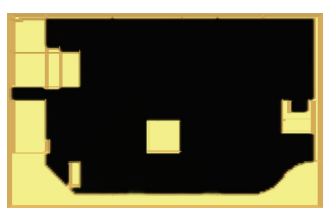

Smoke spreading at $1800 \mathrm{~s}$

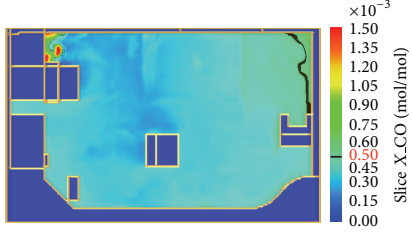

CO distribution at $500 \mathrm{~s}$

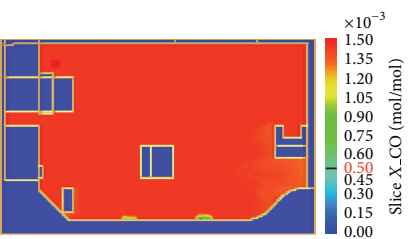

CO distribution at $1800 \mathrm{~s}$

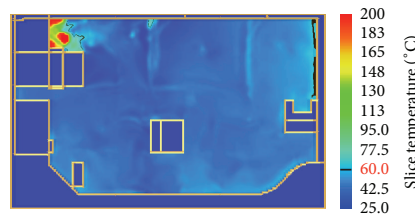

Temperature distribution at $500 \mathrm{~s}$

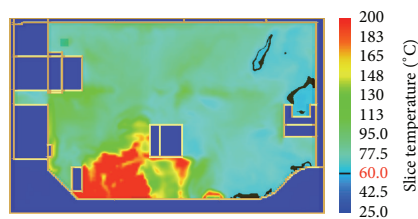

Temperature distribution at $1800 \mathrm{~s}$

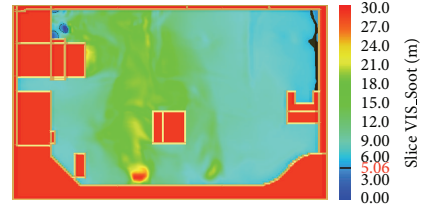

Visibility distribution at $500 \mathrm{~s}$

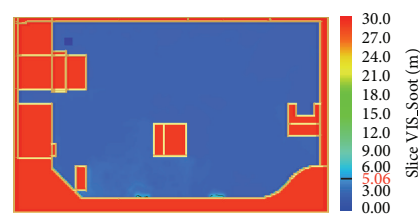

Visibility distribution at $1800 \mathrm{~s}$

FIGURE 2: Smoke hazards change with time and spatial position predicted by FDS.

rectangle warehouse with $3500 \mathrm{~m}^{2}$ area and $5 \mathrm{~m}$ height. The smoke spreading, smoke layer's temperature, smoke layer's toxicity, and smoke layer's visibility are clearly shown in Figure 2. From Figure 2, we can see that the distributions of smoke hazards change with time and spatial position and large eddy simulation technology of FDS could accurately predict these hazards distributions in the whole process of localized fire.

3.2. Quantitative Analysis of Structural Stability. As stated above, the steel structure may collapse when the temperature of steel numbers exceeds $350^{\circ} \mathrm{C}$. So we can treat the time when the steel numbers reach $350^{\circ} \mathrm{C}$ as the time of structural instability. Thus, a modified model of steel temperature rise is proposed in this section to predict the time when the steel numbers reach $350^{\circ} \mathrm{C}$ in oversized spaces.

Similar to the classical model of steel temperature rise in normal enclosure, an assumption is also made that the steel numbers are black bodies for conveniently studying the heat transfer between steel numbers and fire. Moreover, because of relatively high conductivity, implying uniform temperature in the steel section is widely used. The thermal equilibrium equation is built as follows [21]:

$$
Q_{s}=V_{s} \rho_{s} C_{s} \frac{d T_{s}}{d t},
$$

where $Q_{s}$ is the net heat flux, $\mathrm{kW}, V_{s}$ is the volume of steel, $\mathrm{m}^{3}$, $\rho_{s}$ is the density of steel, $\mathrm{kg} \cdot \mathrm{m}^{-3}, T_{s}$ is the steel temperature, ${ }^{\circ} \mathrm{C}$, and $C_{s}$ is the specific heat of steel, $\mathrm{J} /\left(\mathrm{kg} .{ }^{\circ} \mathrm{C}\right)$.

As discussed above, the heat transfer between steel numbers and fire in oversized spaces contains three parts: smoke thermal convection, smoke thermal radiation, and flame thermal radiation, as shown in Figure 3. The net absorbed heat of steel members could be calculated by

$$
Q_{s}=\left(Q_{g r}+Q_{f r}+Q_{s c}\right) \varepsilon_{s},
$$

where $Q_{g r}$ is the smoke radiation heat, $\mathrm{kW}, \mathrm{Q}_{f r}$ is the flame radiation heat, $\mathrm{kW}$, and $Q_{s c}$ is the smoke convention heat, $\mathrm{kW}$,

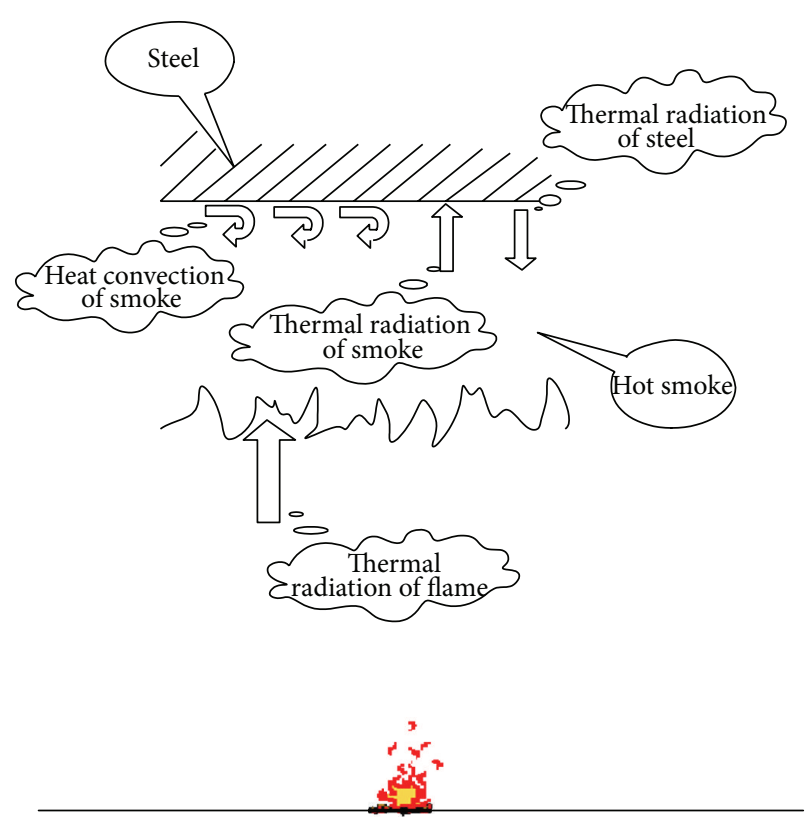

Figure 3: Heat balance of steel components.

and $\varepsilon_{s}$ is a correction factor which is used to correct the net absorbed heat.

The smoke convection heat and smoke radiation heat could be separately evaluated by (12) on the basis of the classical steel temperature rise models as follows:

$$
\begin{aligned}
Q_{g r} & =\sigma_{0} F_{s} \varepsilon_{g}\left[\left(T_{g}+273\right)^{4}-\left(T_{s}+273\right)^{4}\right], \\
Q_{s c} & =F_{s} \alpha_{c}\left(T_{g}-T_{s}\right),
\end{aligned}
$$

where $F_{s}$ is the external surface area of steel numbers, $\mathrm{m}^{2}$, $\varepsilon_{g}$ is the effective emissivity of smoke, $T_{g}$ is the smoke temperature, ${ }^{\circ} \mathrm{C}, \sigma_{0}$ is Stefan-Boltzmann constant, $5.67 \times$ $10^{-8} \mathrm{~W} / \mathrm{m}^{2} \cdot \mathrm{K}^{4}, \alpha_{c}$ is the convective heat transfer coefficient, 


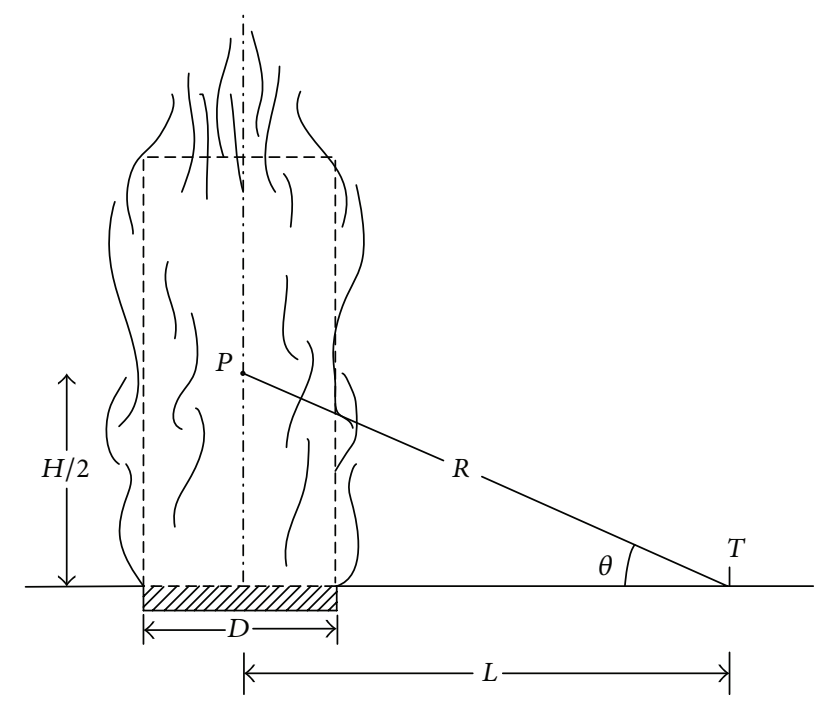

FIGURE 4: Thermal radiation of point fire source.

and recommended value of $\alpha_{c}$ is $25 \mathrm{~W} /\left(\mathrm{m}^{2} \cdot{ }^{\circ} \mathrm{C}\right)$ in $\mathrm{EN} 1993-$ 1-2:2005.

Localized fire in oversized spaces can be treated as a single-point source located at the center of flames which is proposed in the SFPE (Society of Fire Protection Engineers) handbook. The point fire source releases radiation heat to global surroundings and the radiation heat a target receives can be evaluated by

$$
q=\frac{Q_{f}}{4 \pi R^{2}}
$$

where $q$ is radiation heat flux, $\mathrm{kW} / \mathrm{m}^{2} ; R$ is the distance from the point source, $p$, to the target as shown in Figure $4 ; Q_{f}$ is radiation heat of the fire source, $\mathrm{kW}$. Yang et al. [22] and Hiroshi and Taro [23] have given the calculation method for $Q_{f}$ by lots of experiments as follows:

$$
Q_{f}=Q \times 0.35 e^{-0.05 D},
$$

where $Q$ is heat release rate of fire, $\mathrm{kW} ; D$ is the equivalent diameter of the fire source, $m$.

Not all external surfaces could receive radiation heat from flame, so one shape factor should be used to correct the effective surface area. Meanwhile, part of the incident radiation heat flux is absorbed by the smoke layer. Therefore, the radiation flux that steel members receive from flames should be corrected as $\left(1-a_{g}\right) q$. Thus, the radiated heat received by steel members at distance $R$ away from the fire source can be calculated by

$$
Q_{f r}=F_{s} \gamma \times\left(1-a_{g}\right) \times \frac{Q \times 0.35 e^{-0.05 D}}{4 \pi R^{2}},
$$

where $\gamma$ is shape factor, $\alpha_{g}$ is the smoke absorptivity, and [24] have given an empirical equation for smoke absorptivity as follows:

$$
\alpha_{g}=0.458-1.29 \times 10^{-4} T_{g}
$$

Combining (10) with (16), the steel temperature rise exposed to localized fire in oversized spaces could be evaluated by

$$
\begin{gathered}
\Delta T=\frac{\varepsilon_{s} F_{s} \Delta t}{V_{s} \rho_{s} C_{s}} \\
\times\left[\sigma_{0} \varepsilon_{g}\left(\left(T_{g}+273\right)^{4}-\left(T_{s}+273\right)^{4}\right)+\alpha_{c}\left(T_{g}-T_{s}\right)\right. \\
\left.+\frac{\gamma\left(1-a_{g}\right) Q \times 0.35 e^{-0.05 D}}{4 \pi R^{2}}\right] .
\end{gathered}
$$

Two verification experiments were conducted in an oversized space to verify the accuracy of the proposed model. The experimental steel was an I beam with $1.60 \mathrm{~m}$ length, $0.15 \mathrm{~m}$ height, $0.61 \mathrm{~m}$ section perimeter, and $50 \mathrm{~kg}$ weight per meter. Diesel fuel was placed on weighing sensor as pool fire. $K$-type thermocouples are used to record the smoke temperature $T_{g}$ and steel temperature $T_{s}$ in the experiments. The classical model (flame thermal radiation is not considered) and proposed modified model (flame thermal radiation is considered) are separately used to predict the steel temperature curves in the experiments. From the predicted results shown in Figure 5, we can see that both the classical and the modified models are able to predict the steel temperature curve in fire experiments. The maximum error using the classical model is $1.88^{\circ} \mathrm{C}$, while that using the modified model is only $0.93^{\circ} \mathrm{C}$. Thus, we can see that the proposed modified model can more accurately predict the temperature curves of the steel members exposed to localized fire in oversized spaces.

\section{Quantitative Analysis of Evacuation Process}

The time needed for evacuation $T_{\text {REST }}$ is divided in three parts: fire alarm time, response delay time, and personnel evacuation time, as represented by

$$
T_{\mathrm{RSET}}=T_{d}+T_{d e}+k \cdot T_{t}
$$

where $T_{d}$ represents fire alarm time, $s ; T_{d e}$ represents the response delay time, $s$; $T_{t}$ represents the evacuation movement time, s. Given that each evacuation model is established on the basis of a certain assumptions and represents an ideal evacuation, a safety coefficient $k$ is frequently adopted accounting for discrepancies between an ideal evacuation process and an actual one.

Pathfinder, one graphical-interface dynamic evacuation simulation software, can be used for evacuation analysis in various fire situations. Pathfinder provides an SFPE mode which implements the flow-based egress modeling techniques presented in the SFPE handbook of fire protection engineering [25]. The SFPE calculation is a flow model, where walking speeds and flow rates through doors and corridors are defined. Each occupant has a specified maximum evacuation speed in this model. If the population density is less than 0.55 persons $/ \mathrm{m}^{2}$, evacuees will evacuate at their own pace with maximum evacuation speed. If the population 

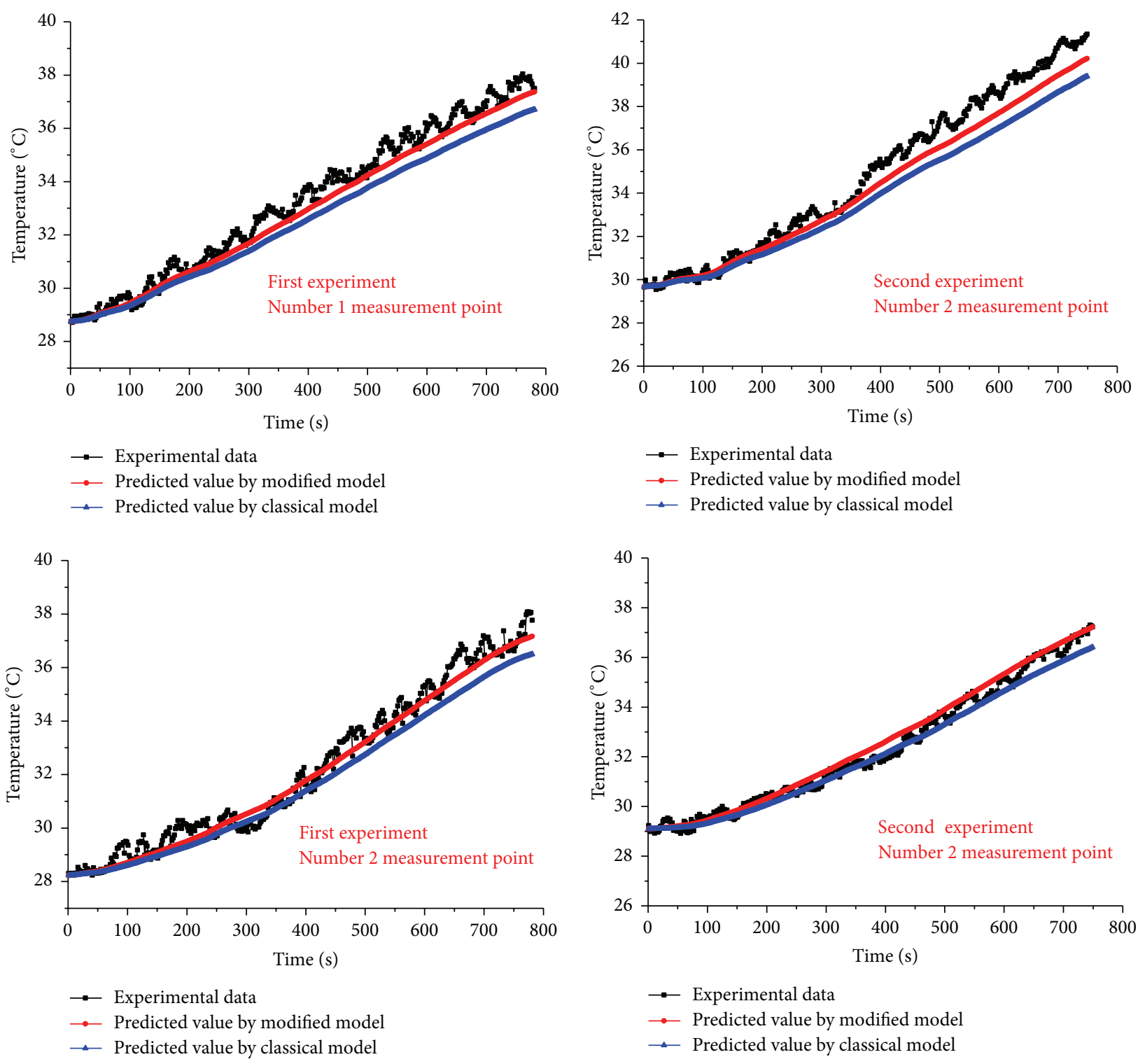

FIGURE 5: Predictive values of the steel temperatures.

density exceeds 3.8 persons $/ \mathrm{m}^{2}$, no movement will take place. Between the density limits of 0.55 and 3.8 persons $/ \mathrm{m}^{2}$, the relationship between evacuation speed and density can be calculated by

$$
v=1.4 v_{\max } \frac{1-0.266 D}{1.19},
$$

where $v$ is the movement speed, $\mathrm{m} / \mathrm{s} ; D$ is population density, person $/ \mathrm{m}^{2} ; v_{\max }$ is the maximum evacuation speed, $\mathrm{m} / \mathrm{s}$. And Shi et al. recommend maximum evacuation speed for different occupant types, as shown in Table 2 [26].

Another parameter in simulating evacuation is specific flow. Specific flow is the flow of evacuating persons past a point in the exit route second per unit of effective width which could be predicted by

$$
F=1.4(1-0.266 D) D,
$$

where $F$ is specific flow.
TABLE 2: Maximum evacuation speed of different occupant types.

\begin{tabular}{lcccc}
\hline Occupant types & Children & $\begin{array}{c}\text { The } \\
\text { elderly }\end{array}$ & $\begin{array}{c}\text { Female } \\
\text { adult }\end{array}$ & $\begin{array}{c}\text { Male } \\
\text { adult }\end{array}$ \\
\hline $\begin{array}{l}\text { Maximum } \\
\text { evacuation speed } \\
(\mathrm{m} / \mathrm{s})\end{array}$ & 1.08 & 1.04 & 1.24 & 1.30 \\
\hline
\end{tabular}

In order to further validate the accuracy of Pathfinder in predicting the evacuation movement time, we conducted a study on stadium evacuation as shown in Figure 6. In the experiment, the total number of evacuated people was 2,086 , the total time of evacuation was $182 \mathrm{~s}$, and the total flow coefficient of evacuation exits was 0.80 person/(s.m). The utilization rates of various evacuation exits were basically the same and their average flow coefficients all fell between 0.80 person/(s.m) and 0.87 person/(s.m). In the numerical 

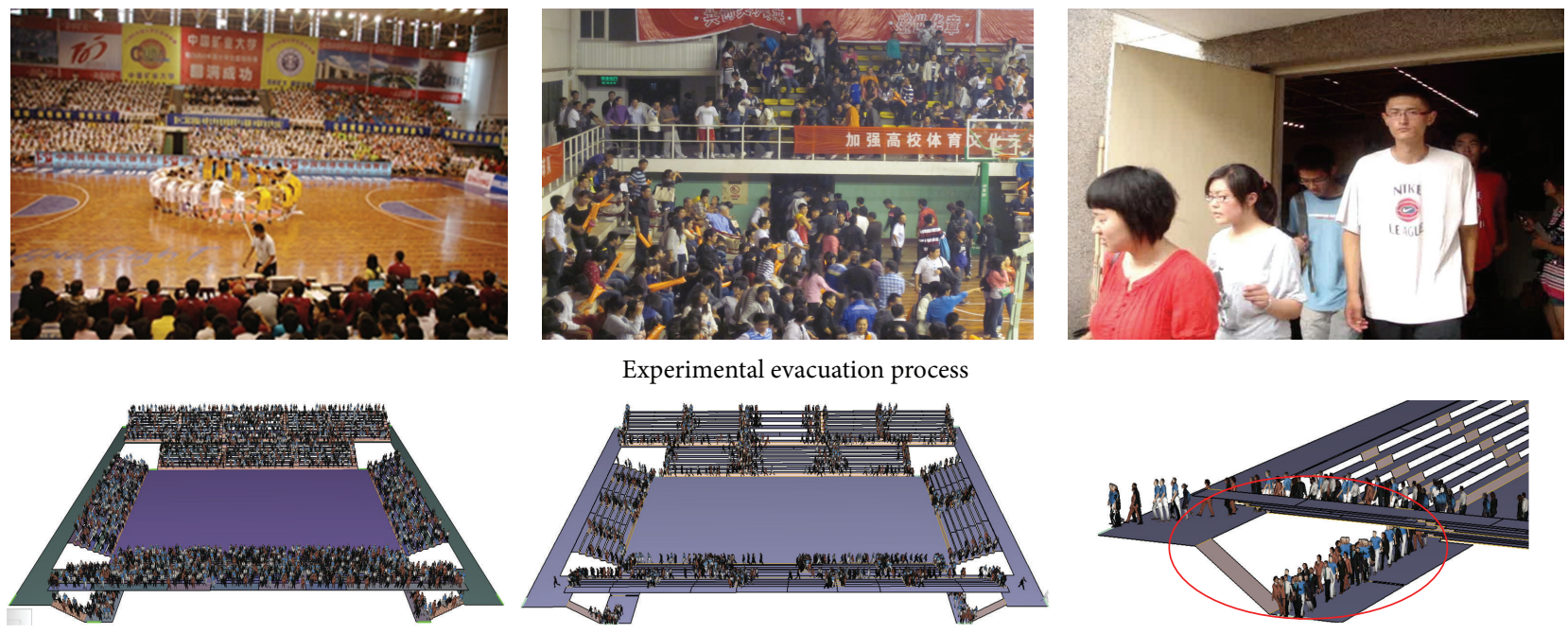

Numerical evacuation process

FIGURE 6: Experimental evacuation process and numerical evacuation process.

analysis of the evacuation time of the stadium through Pathfinder simulation, the evacuation movement time obtained was $147 \mathrm{~s}$, and the flow coefficients of various safety exits were consistent with the experimental data. However, the flow coefficients of various exits obtained by computer simulation were slightly greater (compared to the average flow coefficient of 1.08 person/(s.m)). Thus, for the purpose of conservative prediction in the quantitative analysis of evacuation from oversized buildings, we propose that the evacuation time obtained by Pathfinder simulation be multiplied by a factor of 1.5; that is, $k=1.5$.

\section{Case Study}

An exhibition center is an oversized steel-framed building. It is $50 \mathrm{~m}$ in length, $50 \mathrm{~m}$ in width, and $8 \mathrm{~m}$ in height. The building is enclosed all around with reinforced concrete. It is built with a steel truss-structured roof and has two safety exits, each of which is $8.5 \mathrm{~m}$ in width. The exhibition center is mainly used for wooden exhibits, and the statistical results indicate that the maximum heat release rate $\left(Q_{\max }\right)$ of a possible fire is $18,684 \mathrm{~kW}$ with a fire development coefficient $(\alpha)$ of $0.00346 \mathrm{~kW} / \mathrm{s}^{2}$. The basic parameters of the steel member include $F_{s} / V_{s}=132 \mathrm{~m}^{-1}, \alpha_{c}=25$, and $\rho_{s}=7850 \mathrm{~kg}$. $\mathrm{m}^{-3}$. The total number of people to be evacuated from the exhibition center was 1800 . The total time of a possible fire $\left(t_{s}\right)$ is $5400 \mathrm{~s}$ and the time when the possible fire enters the decay phase $\left(t_{d}\right)$ is $3763 \mathrm{~s}$. We will analyze the fire risk inside the building when a fire occurs in a central location.

Firstly, the fire development model inside the exhibition center is built as described in (21) determined with reference to $(2)$.

Consider

$$
\begin{gathered}
Q=0.0346 t^{2} \quad 0 \leq t \leq 735, \\
Q=18684 \quad 735 \leq t \leq 3763, \\
Q=61633-\frac{18684}{1637} t \quad 3763 \leq t \leq 5400 .
\end{gathered}
$$

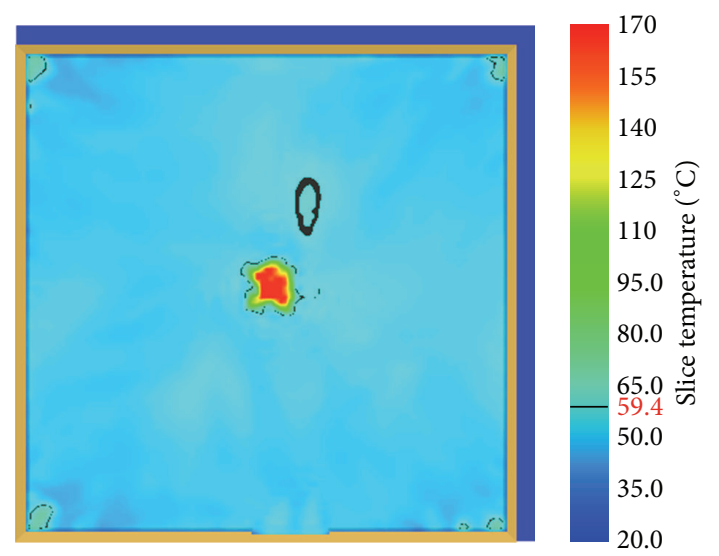

Figure 7: Temperature distribution at $670 \mathrm{~s}$.

Based on the designed fire development model, FDS large eddy simulation was used for the quantitative analysis of smoke hazards in this fire scenario. The simulation results are shown in Figures 7, 8, and 9. From Figures 7-9 we can see that the smoke temperature in the noncombusting region reached its critical value at $670 \mathrm{~s}$ and the smoke visibility reached its critical value at $420 \mathrm{~s}$, while the $\mathrm{CO}$ concentration reached its critical value at $830 \mathrm{~s}$. Therefore, the occurrence time of smoke hazards is $420 \mathrm{~s}$.

Secondly, applying steel temperature rise model proposed in this paper to predict the steel temperature curve in this designed fire scenario, we can obtain the steel temperature curves, as shown in Figure 10. Figure 10 show that the temperature of steel members first increased, then gradually stabilized, and finally reduced, corresponding to the three stages of a fire. The steel numbers reached their critical value at $1230 \mathrm{~s}$. Therefore, we can hold that the time of structural collapse is $1230 \mathrm{~s}$. 


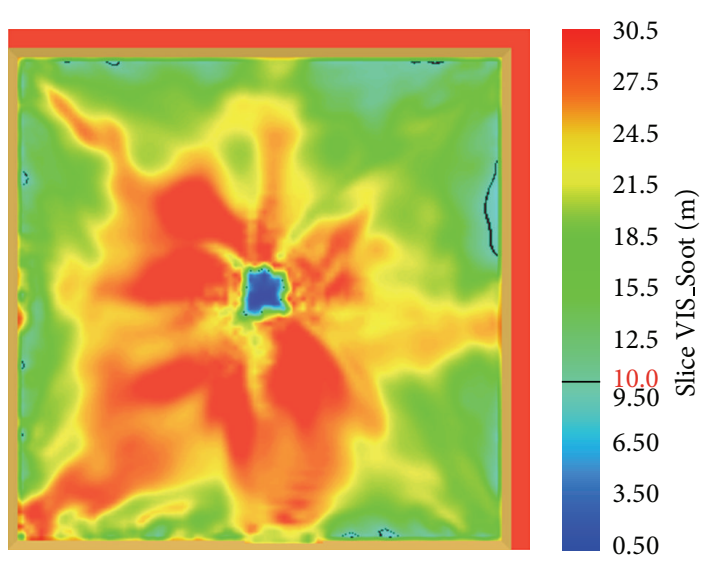

Figure 8: Visibility distribution at $420 \mathrm{~s}$.

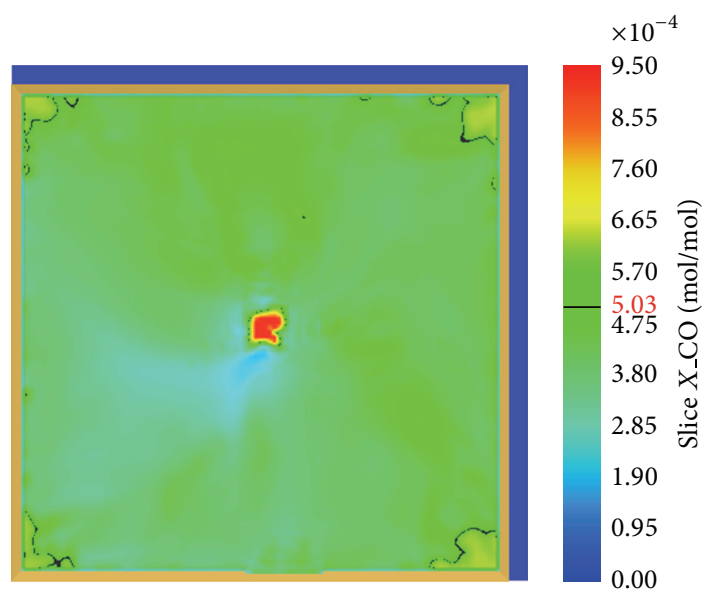

Figure 9: CO distribution at $830 \mathrm{s.}$

Thirdly, we assume that the people requiring evacuation were evenly distributed in the exhibition center and in a sober state. They began their evacuation upon hearing the alarm within a given time and chose the nearest exit for evacuation based on the shortest path. Based on SFPE handbook, the parameters of the exhibition center were determined as $T_{d}=60 \mathrm{~s}$ and $T_{d e}=120 \mathrm{~s}$. The total number of people to be evacuated was set at 1,800 . They were divided into four categories: adult males, adult females, the elderly, and children. The specific categories and proportions are shown in Table 3. Then the evacuation model was established using Pathfinder. The evacuation process is shown in Figures 11 and 12. The evacuation movement time $T_{t}$ was $107.5 \mathrm{~s}$, and the time needed for evacuation as determined by (18) was $341.3 \mathrm{~s}$.

We found through the above study that the occurrence times of smoke hazards is $420 \mathrm{~s}$, the time of structural collapse is $1230 \mathrm{~s}$, and the time needed for evacuation from the building was $341.3 \mathrm{~s}$. From a comparison between the times available for evacuation and the time needed for evacuation, the people inside the exhibition center can be safely evacuated to outdoor. However, after $1,230 \mathrm{~s}$ there may be the risk of structural collapse which is dangerous for firefighters in the rescue process. Thus, firefighters must evacuate to outdoor

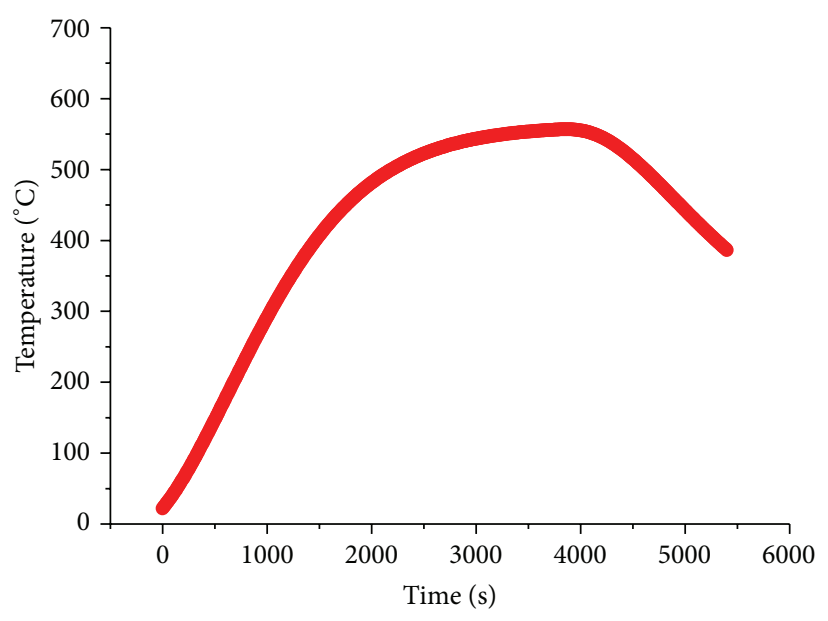

FIGURE 10: Steel temperature curves.

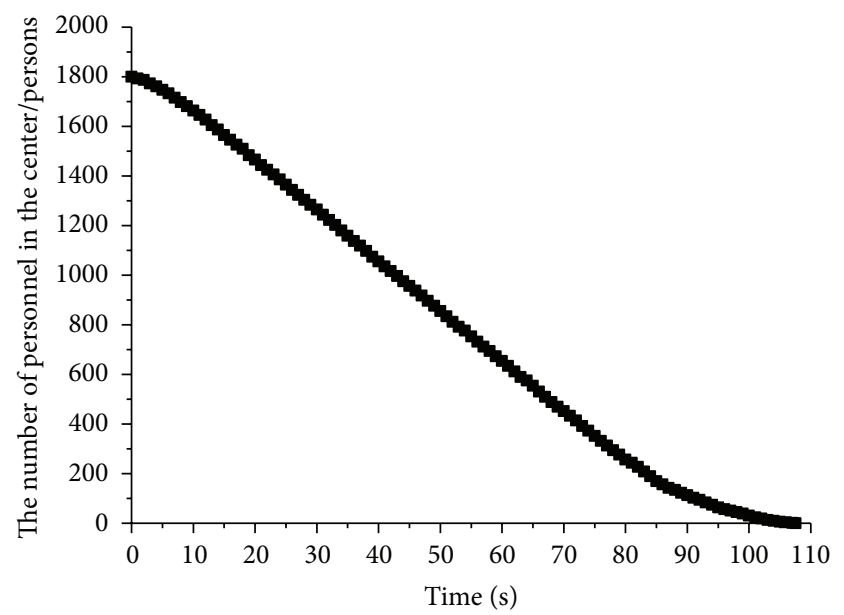

FIGURE 11: The number of personnel in the exhibition center.

TABLE 3: Categories and proportions of people to be evacuated.

\begin{tabular}{lcccc}
\hline Category & Adult male & $\begin{array}{c}\text { Adult } \\
\text { female }\end{array}$ & The elderly & Children \\
\hline Proportions & $40 \%$ & $40 \%$ & $10 \%$ & $10 \%$ \\
\hline
\end{tabular}

after $1230 \mathrm{~s}$ to avoid injuries or death caused by building collapse.

\section{Conclusion}

(1) Our paper proposes a systematic quantitative analysis for fire hazards in oversized steel-framed buildings by adopting a performance-based approach. In the first place, we put forth the method of performance-based fire design of steel structures and defined the safety objectives in the performance-based fire design of oversized steel-framed buildings. In order to achieve the stated objectives, we also proposed performance criteria that must be met. By comparing the occurrence times of various hazards (smoke temperature, 


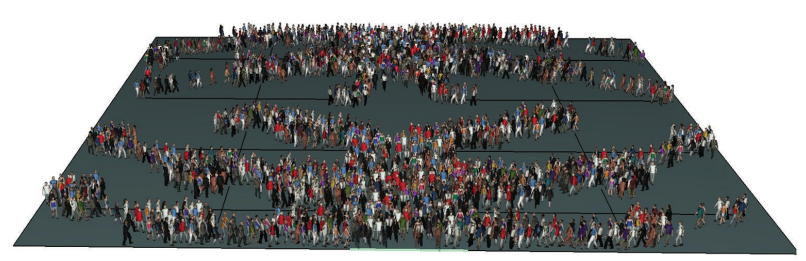

$t=10 \mathrm{~s}$

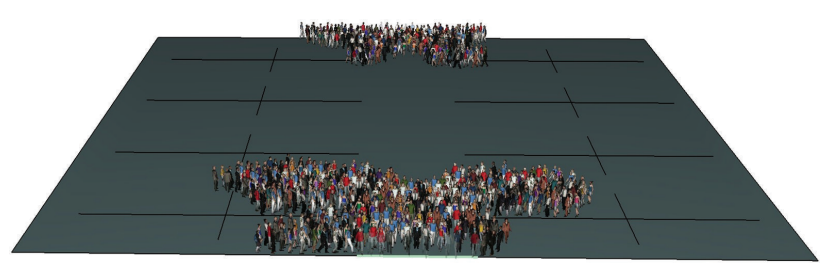

$t=60 \mathrm{~s}$

FIGURE 12: Evacuation process of the exhibition center.

visibility, toxicity, and structural collapse) and the time needed for safe evacuation, a quantitative evaluation can be conducted on building evacuation. In addition, the time available for safe evacuation provides a theoretical reference for emergency rescuers.

(2) We propose a method to predict the time available for evacuation and use FDS large eddy simulation to quantitatively analyze smoke temperature, visibility, and toxicity in the fire. Meanwhile, our paper also put forth the temperature rise model of oversized steel structure in a fire, which took into consideration not only the effects of the thermal radiation and convection of smoke on steel components but also the thermal effect of flame radiation. We found through experimental validation that the proposed modified temperature rise model of steel components can more accurately predict the temperature rise of steel components than the classic model.

(3) Furthermore, we also study evacuation from an oversized building. We find through an experimental evacuation study that the Pathfinder model developed on the basis of water conservation model and behavior model can be used to predict evacuation from an oversized building. The flow coefficients of various safety exits obtained through simulation by Pathfinder software are basically consistent with our experimental data. However, the flow coefficients of various exits obtained by computer simulation are slightly greater. Thus, we suggest that the evacuation movement time obtained by computer simulation be adjusted by a factor of 1.5 .

\section{Conflict of Interests}

The authors declare that there is no conflict of interests regarding the publication of this paper.

\section{Acknowledgments}

The research presented in this paper was supported by the open foundation of Jiangsu Key Laboratory for Environmental Impact and Structural Safety in Civil Engineering (JSKL2011YB11), the Specialized Research Fund for the Doctoral Program of Higher Education (Grant no. 20120032110045), and the National Natural Science Foundation of China (Grant no. 51208504).

\section{References}

[1] J. T. Gerlich, P. C. R. Collier, and A. H. Buchanan, "Design of light steel-framed walls for fire resistance," Fire and Materials, vol. 20, no. 2, pp. 79-96, 1996.

[2] J. I. Ghojel and M. B. Wong, "Heat transfer model for unprotected steel members in a standard compartment fire with participating medium," Journal of Constructional Steel Research, vol. 61, no. 6, pp. 825-833, 2005.

[3] M. M. S. Dwaikat and V. K. R. Kodur, "A simplified approach for predicting temperature profile in steel members with locally damaged fire protection," Fire Technology, vol. 48, no. 2, pp. 493512, 2012.

[4] T. R. Kay, B. R. Kirby, and R. R. Preston, "Calculation of the heating rate of an unprotected steel member in a standard fire resistance test," Fire Safety Journal, vol. 26, no. 4, pp. 327-350, 1996.

[5] L. Gardner and K. T. Ng, “Temperature development in structural stainless steel sections exposed to fire," Fire Safety Journal, vol. 41, no. 3, pp. 185-203, 2006.

[6] F. Wald, M. Chladná, D. Moore, A. Santiago, and T. Lennon, "Temperature distribution in a full-scale steel framed building subject to a natural fire," Steel and Composite Structures, vol. 6, no. 2, pp. 159-182, 2006.

[7] B. Barthelemy, "Heating calculation of structural steel members," Journal of the Structural Division, vol. 102, no. 8, pp. 15491558, 1976.

[8] J. Shi, X. Sun, W. Liu, and Y. Li, "Study of performance-based fire resistance design methodology for large space structures," China Civil Engineering Journal, vol. 44, no. 5, pp. 69-78, 2011.

[9] A. Rubert and P. Schaumann, "Structural steel and plane frame assemblies under fire action," Fire Safety Journal, vol. 10, no. 3, pp. 173-184, 1986.

[10] Y. C. Wang, "An analysis of the global structural behaviour of the Cardington steel-framed building during the two BRE fire tests," Engineering Structures, vol. 22, no. 5, pp. 401-412, 2000.

[11] Y. C. Wang and V. K. R. Kodur, "Research toward use of unprotected steel structures," Journal of Structural Engineering, vol. 126, no. 12, pp. 1442-1450, 2000.

[12] F. Wald, L. Simões da Silva, D. B. Moore et al., "Experimental behaviour of a steel structure under natural fire," Fire Safety Journal, vol. 41, no. 7, pp. 509-522, 2006.

[13] J. M. Franssen, G. M. E. Cooke, and D. J. Latham, "Numerical simulation of a full scale fire test on a loaded steel framework," Journal of Constructional Steel Research, vol. 35, no. 3, pp. 377408, 1995.

[14] M. B. Wong, "Elastic and plastic methods for numerical modelling of steel structures subject to fire," Journal of Constructional Steel Research, vol. 57, no. 1, pp. 1-14, 2001. 
[15] The Chartered Institution of Building Services Engineers Delta House, CIBSE, Relationships for smoke control calculations, 1995.

[16] G. V. Hadjisophocleous and N. Benichou, "Performance criteria used in fire safety design," Automation in Construction, vol. 8, no. 4, pp. 489-501, 1999.

[17] British Standards Institution, EN C. 1-2, Eurocode 3: Design of steel structures, part 1-2: General Rule-Structural Fire Design, British Standards Institution, London, UK, 2005.

[18] Z. Guowei, Z. Guoqing, Y. Guanglin, and H. Lili, "Methods for prediction of steel temperature curve in the whole process of a localized fire in large spaces," Mathematical Problems in Engineering, vol. 2014, Article ID 238515, 12 pages, 2014.

[19] T. G. Ma and J. G. Quintiere, "Numerical simulation of axisymmetric fire plumes: accuracy and limitations," Fire Safety Journal, vol. 38, no. 5, pp. 467-492, 2003.

[20] T.-S. Shen, Y.-H. Huang, and S.-W. Chien, "Using fire dynamic simulation (FDS) to reconstruct an arson fire scene," Building and Environment, vol. 43, no. 6, pp. 1036-1045, 2008.

[21] Z. Guo-wei, Z. Guo-qing, and H. Li-li, "Temperature rise in steel members exposed to localized fire in large enclosure," Safety Science, vol. 62, pp. 319-325, 2014.

[22] J. C. Yang, A. Hamins, and T. Kashiwagi, "Estimate of the effect of scale on radiative heat loss fraction and combustion efficiency," Combustion Science and Technology, vol. 96, no. 1-3, pp. 183-188, 1994.

[23] K. Hiroshi and Y. Taro, "Air entrainment and thermal radiation from heptane pool fires," Fire Technology, vol. 24, no. 1, pp. 3347, 1988.

[24] D. K. Edwards and R. Matavosian, "Scaling rules for total absorptivity and emissivity of gases," Journal of Heat Transfer, vol. 106, no. 4, pp. 684-689, 1984.

[25] G. Proulx, "Movement of people: the evacuation time," in The SFPE Handbook of Fire Protection Engineering, W. D. Walton, Ed., pp. 876-901, NFPA, Quincy, Mass, USA, 3rd edition, 2002.

[26] L. Shi, Q. Xie, X. Cheng, L. Chen, Y. Zhou, and R. Zhang, "Developing a database for emergency evacuation model," Building and Environment, vol. 44, no. 8, pp. 1724-1729, 2009. 


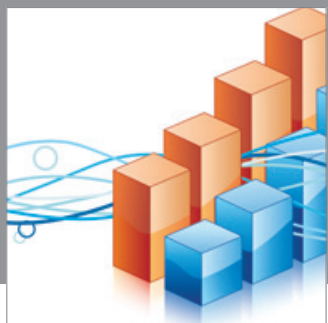

Advances in

Operations Research

mansans

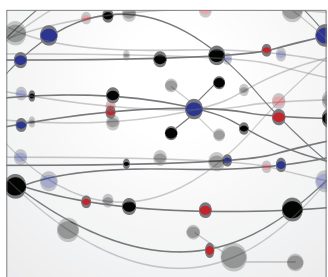

The Scientific World Journal
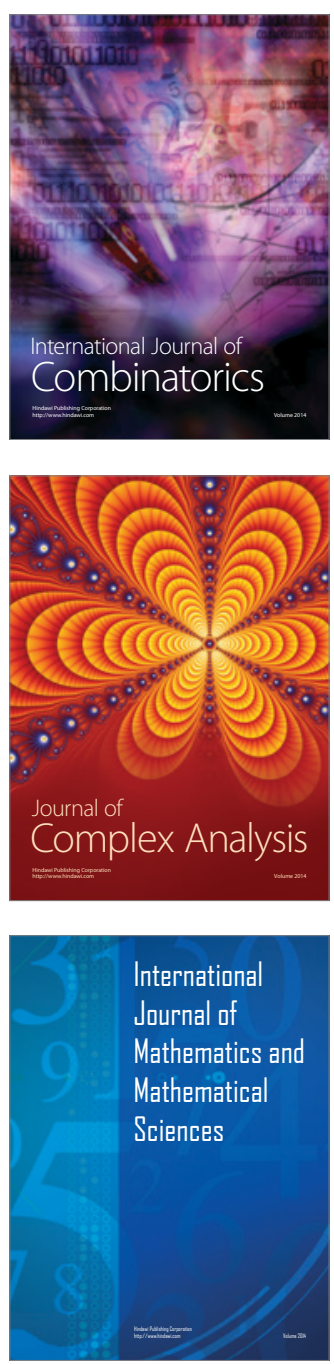
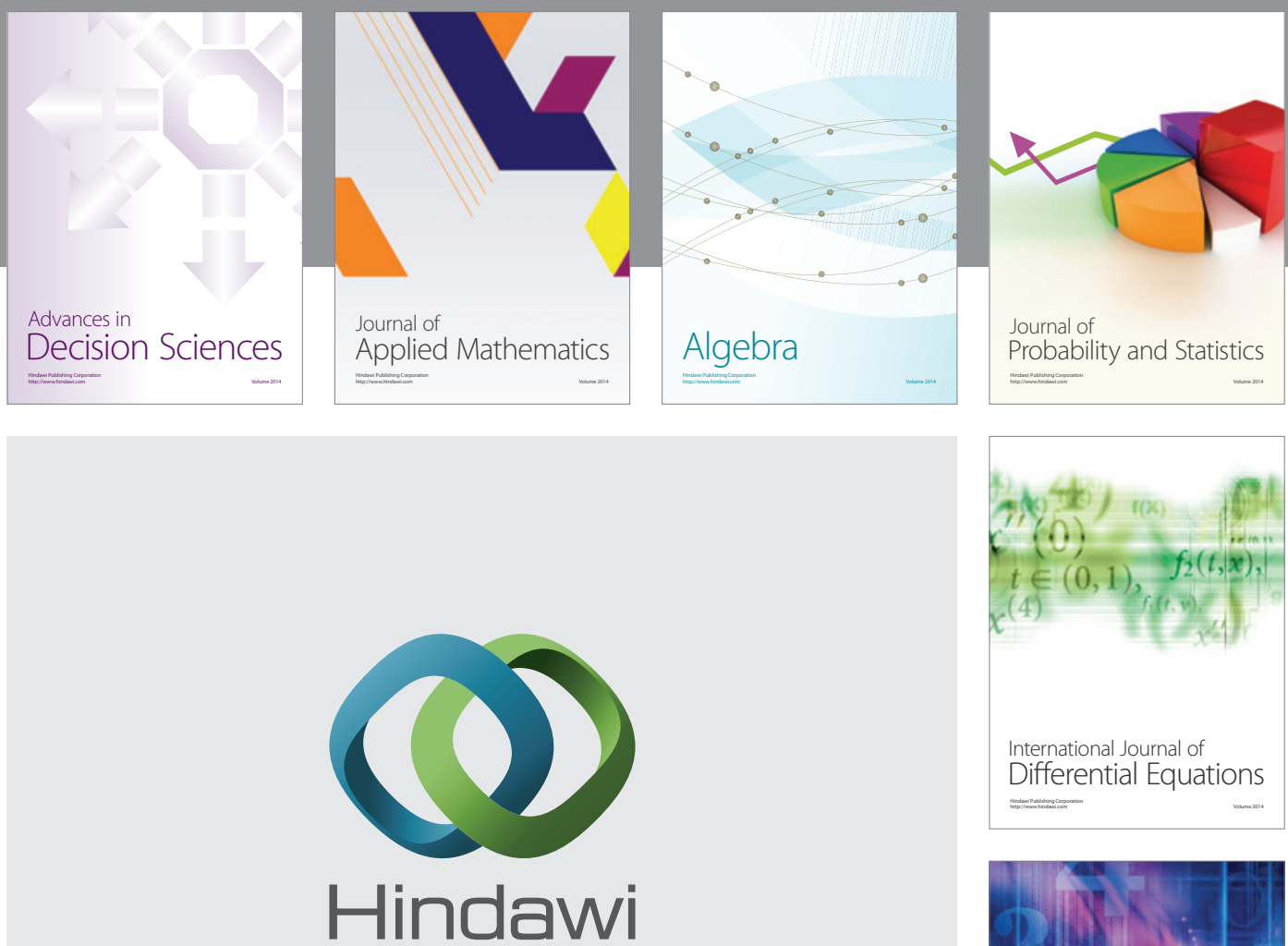

Submit your manuscripts at http://www.hindawi.com
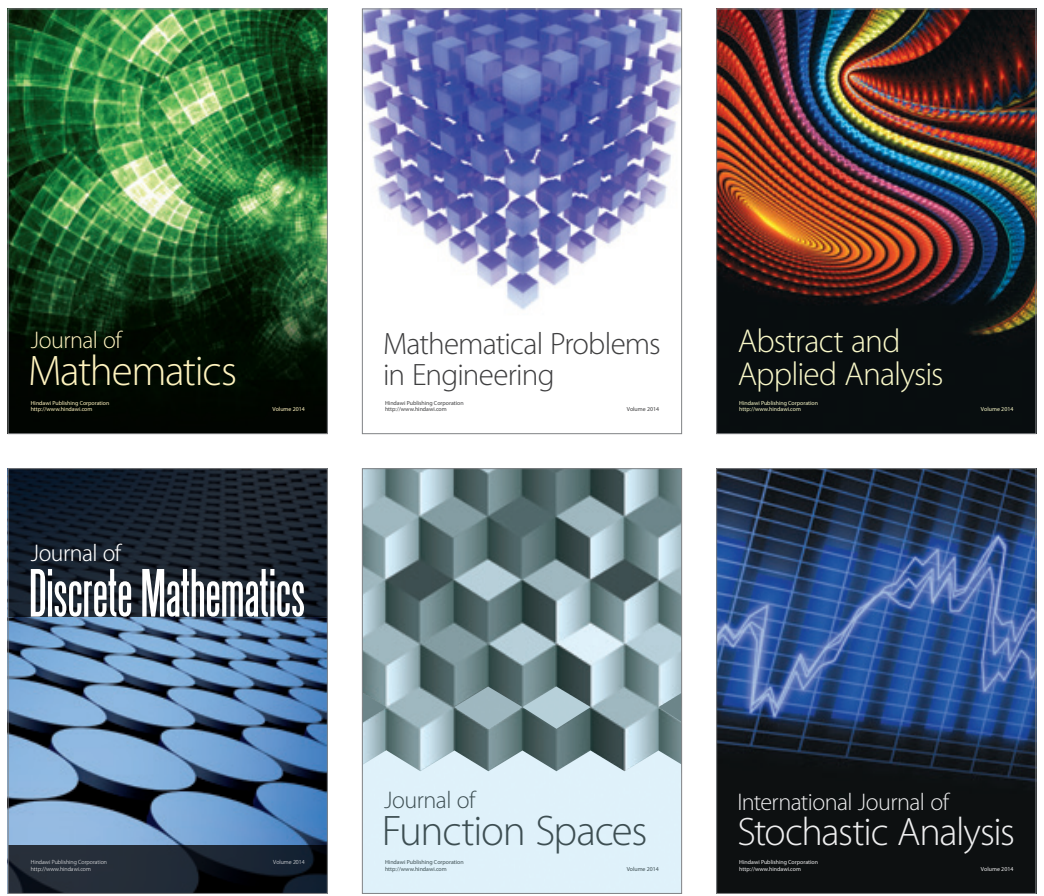

Journal of

Function Spaces

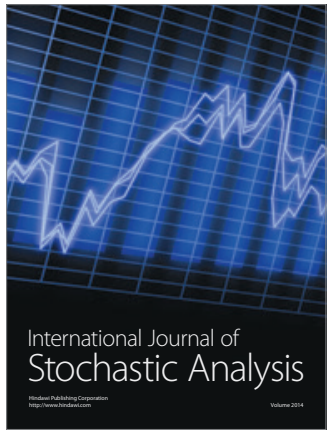

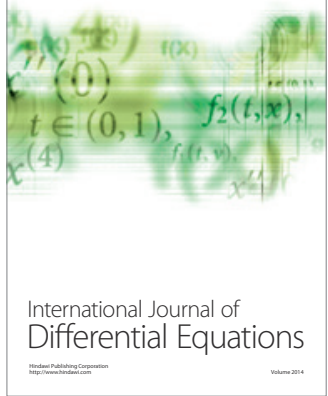
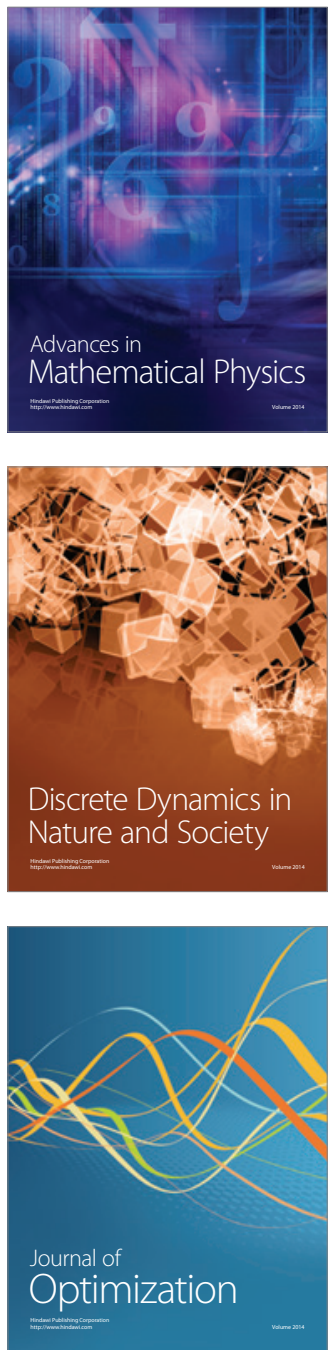